\section{CASES OF RESUSCITATION.}

Dy I M.trer Mackinder, M.D., F.R.C.S.Edin., Gainsborough. Or resuscitation by the plan of the late Dr. Marshall Hall, so many rases have now been recorled, that it seems alnost necrising to apologise for reporting any more. Yet, on matter if such importance, it were well that we should not entirely avoid its discussion uritil the public are fully acquainted with the scientific principles on which the "ready method" is foumich, and every man and womsn prepared to exercise the physician's function in the revivifying of an unfortunate fellow creature who, from some inauspicious cireumstance, may have fallen into a state of suspenled animation.

Though the "ready method" will not alwars be attended with sncees;, it may fairly be considered the hest and simplest of all known means for relindling the vital spark, and the facility of its application will render its adoption universal, when the public cone to understand and apprecinte the discovery.

It vecurred to me the other day, while attending the third case, to be heveafter mentioned, to mive a little clinic to the nurses in attendance; and if the like were done by our associates and medical lirethren in general at every available opportunity, there would soon be a large section of the community conpetent to act in any emergency. liecently, a little child was diowned in a fond in this neighbourhood. Assistance was immediately sought; the body was recovered, and taken home as dead: and who will venture to assert that the pulsation of its heart might not have been re-established, its parents saved the mourning of so untimely and unnatural a death, and the coroner cheated of his fee, had the proper meuns been taken at the moment of the child's removal to the land?

CASE I. Early in the morning of February 5th last, I was summoned to a Mrs. B., of this town, whom I delivered of seven month twins, male and female, the latter being the elder by ten minutes. The boy presented at the feet, and was pulseless when born; but being by far the finer child of the two, and the sex wished for by its father, I determined to resuscitate it if possible, and at once commenced the threequarter rotation, as recommended by Dr. Marshall Hall. This I continued for fifteen minutes without the slightest appearance of vitality. Then, fearing more had been said about the "ready method" than was consistent with truth, or that I had misarprehended the directions of Marshall Hall, I proceeded to inflate with a piece of tobacco-pipe, an instrument well adapted by its suction property to keep the tongue from slipping backwards. The child grew deathly cold, and its extremities became quite livid; but after persevering for twenty minutes with the inflation, it gave a sudden double gasp for breath, which it repeated in five minutes more. This double gasping or sobbing continued at diminishing intervals for thirty minutes longer, during which period I occasionally forced in a little air. Breathing then, to the astonishment of the mother and attendants, became natural, and I committed the child to the custody of the nurse. It died twelve hours afterwards, and its sister in a few days, neither of them possessing sufficient physical power to sustain life.

CASE II. In the evening of the same day, my assistant, Mr. E. Capron, attended a woman at the workhouse. On his arrival, at half-past eight, he found a vertex presentation, with a loop of the funis, the palsation of which hat ceased. "I found it impossible," said Mr. Capron, "to replace the funis and in half an hour the woman was delivered of a child apparently quite dead. The usual means failing to restnre it, I at once commenced the "ready method'." After ten minutes trial, the child gave a feeble gasp, and it continued to do so at every ten or twelve turns. The intervals between these respiratory movements soon became shorter and shorter, and in half an hour it breathed of its own accord. It appeared, however, in a semicomatose state for some time, and was thiee hours before it became warm and could move its limbs. Fven then the heart beat rery feebly, and at half its normal frequency at birth, and it did not entirely recover until six o'clock the following morning." The child went on well, much to the annoyance of its affectionate mother, who exclaimed, that "it was dead once, if that stupid doctor had but left it alone!" This case was communicated to Dr. Marshall Hall, who published it in the Lancet of April 25th.

CASE III. On September 12th, I was sent for to attend a woman of the name of Davey, in her second accouchement. Ou my arrival, I was informed that the infant had been born ten minutes, and that it had only breathed once. Leaving the mother to take care of herself, I immediately divided the finis, and began to resuscitate the cold and pulseless child by the "ready method". To the surprise of the nurse and a friend present, respiration was established in twenty minutes, and the ehild seems now in the enjoyment of vigorous health.

\section{ON THE COMPARATIVE IMMUNITY FROM SMALL- POX OF THOSE WHO HAVE BEEN UNDER THE INFLUENCE OF COW-POX.}

By G. Rignes, Esq., Surgeon to the Canterbury Dispensary. [Recal before the East Kent and Canterbury Medical Society, Session 1856-7.]

Is the 36 th rolume of the Transactions of the Royal Medical and Chirurgical Society is published a very valuable paper on smallpox and vaccination, as observed by Mr. Marson at the smallPox and Vaccination Hospital, between the year's $18: \%$ and 1851 inclusive. From this report, it appears that rather more than half of the patients who came under treatment for smallpox during that period had been previously under the influence of vaccination. It shows, however, further that, while small-pox in the unvaccinated remains as violent and fatal as ever, about one-third of the patients dying, vaccination performed in infancy affords almost complete protection from small-pox until the age of puberty; and even in after ages, the mortality, where there are cicatrices of vaccination remaining, was but $5_{\frac{1}{4}}$ per cent. ; and where there was no cicatrix remaining-and in many of these the evidence of vaccination must have been doubtful - the mortality was but 21 per cent.

During the present year, a very valuable report on this stubject has been published by order of the Board of Health, which proves beyond a doubt the very great advantages of vaccination in infancy; but it moreover proves that small-pox does in all parts of this kingdom, as well as in foreign countries, frequently attack those who from our previous knowledge were considered almost, if not quite, exempt from its influence.

The report I am now about to lay before the members comprises 113 cases of small-pox observed by me in the dwellinghouses of the eity of Canterbury and its vicinity, between March 4th, 1855, and the end of February 1856. Of these cases, 4 occurred in March, 26 in April, 17 in May, 10 in June, 10 in July, 10 in August, 5 in September, 10 in October, 7 in November, 9 in December, 4 in January, and 1 in February 1856 .

These cases occurred in 51 different houses or families. And there were also resident in the same houses 228 other persons who escaped. Of this number, 76 had gone through the disease previously, and 152 had no other apparent protection but that derived from vaccination; in no instance did a person resident in either of the houses escape, unless he or she had been under the influence of one or other form of the disease previously.

Of the total number of cases, 50 were confluent; $1 \tau$ semiconfluent; and 16 distinct : 6 patients died.

Of the patients, 72 had never been vaccinated, and 41 had been vaccinated, mostly in infancy.

Of the 41 patients who had been vaccinated, 24 showed the cicatrices of vaccination, and 17 were more or less indistinct or not traceable. Of these 41 patients, 3 had the disease in a confluent form, 9 had it in a confluent form, but the pustules arrived at maturity at an earlier period, with little or no secondary fever, and are therefore termed modified; 2 were semi-confluent and modified; and $2 \tau$ were distinct and modified.

Of these patients 14 were more than 20 rears of age, 1 was 19 years, 2 were 17,1 was 16 years, 3 were 15 years, 1 was 14 years, 2 were $1: 3$ years, 3 were 12 years, 1 was $11, \pm$ were 10 , 1 was 9,1 was 7,3 were 6,1 was 5 years, 1 was 4,1 was 3 , and 1 was 10 months.

Of these cases four, viz., aged respectively 10 months, 3 years, 4 years, and 7 years, were under the influence of cow-pox and small-pox combined; and one female, ared 15 years, was reported to have been vaccinated in infincy when afflicted also with itch.

Two of the vaccinated patients died, viz., the child aged 10 months, and the young wornan anged 15 years, last alinded to.

The child aged 10 months had small and cow-pox coexisting, but it certainly had been exposed to the infection of the former several days previously to its vaccination for the latter, and neither of these diseases appeared to be modified by the exist- 